\title{
8 The HIRM+ Flight Dynamics Model
}

\author{
Dieter Moormann \\ EADS Deutschland GmbH*^, Military Aircraft \\ MT62 Flight Dynamcis, 81663 München, Germany \\ Dieter.Moormann@m. eads.net
}

\begin{abstract}
Summary. The major objective of the GARTEUR Action Group on Analysis Techniques for Clearance of Flight Control Laws FM(AG-11) is the improvement of the flight clearance process by increased automation of the tools used for modelbased analysis of the aircraft's dynamical behaviour. What is finally needed are techniques for faster detection of the worst case combination of parameter values and manoeuvre cases, from which the flight clearance restrictions are be derived. The basis for such an analysis are accurate mathematical models of the controlled aircraft. In this chapter the HIRM+ flight dynamics model is described as one of the benchmark military aircraft models used within FM(AG-11). HIRM+ originates from the HIRM (High Incidence Research Model) developed within the GARTEUR Action Group on Robust Flight Control FM(AG-08). In building the HIRM+, additional emphasis has been put on realistic modelling of parametric uncertainties.
\end{abstract}

\subsection{Introduction}

The HIRM+ has been developed from the HIRM, a mathematical model of a generic fighter aircraft originally developed by the Defence and Evaluation Research Agency (DERA, Bedford). The HIRM is based on aerodynamic data obtained from wind tunnel tests and flight testing of an unpowered, scaled drop model. The model was set up to investigate flights at high angles of attack $\left(-50^{\circ} \leq \alpha \leq 120^{\circ}\right)$ and over a wide sideslip range $\left(-50^{\circ} \leq \beta \leq+50^{\circ}\right)$, but does not include compressibility effects resulting from high subsonic speeds. The origin of the model explains the unconventional configuration with both canard and tailplane, plus an elongated nose (see Fig. 8.1).

The aircraft is basically stable. However, there are combinations of angle of attack and control surface deflections, which cause the aircraft to become unstable longitudinally and/or laterally. Engine, actuator and sensor dynamics models have been added within FM-AG-08 to create a representative, nonlinear simulation model of a twin-engined, modern fighter aircraft. The model building was done by using the object-oriented equation-based modelling environment Dymola [4].

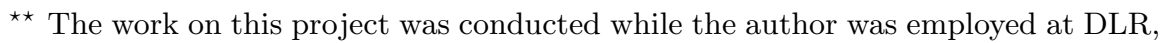
Institute of Robotics and Mechatronics, Oberpfaffenhofen, 82234 Wessling, Germany
} 

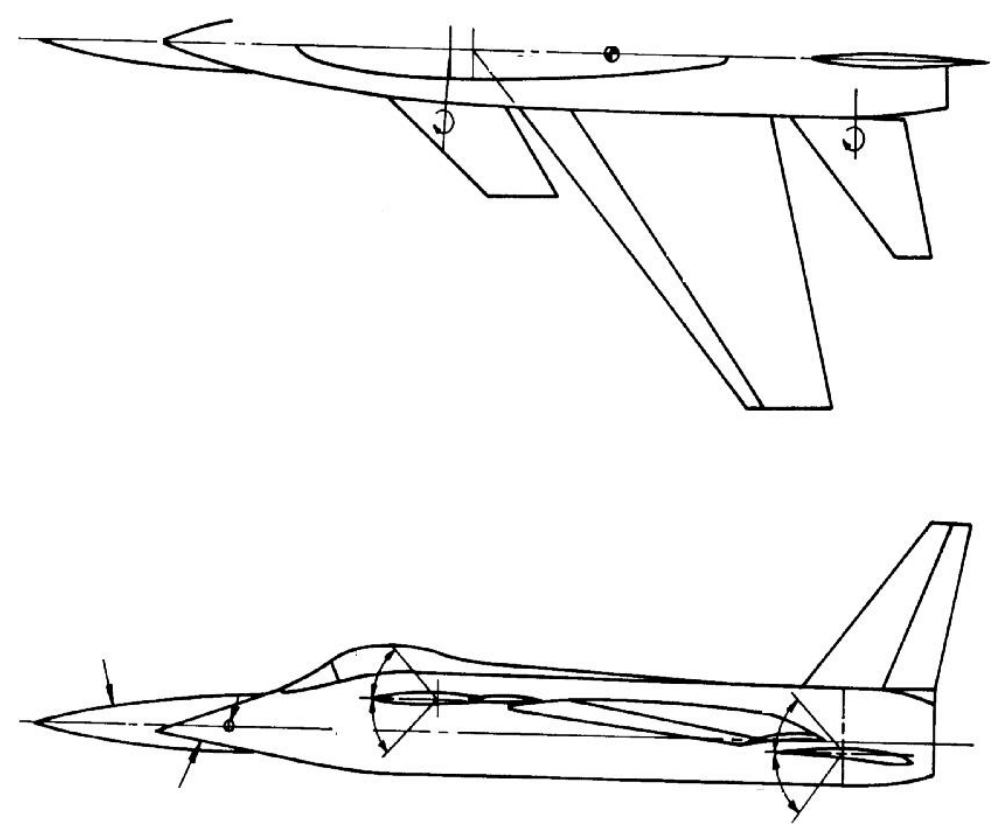

Fig. 8.1. High Incidence Research Model [1]

In building the HIRM+, the emphasis has been put on realistic modelling of parametric uncertainties. Parameters have been defined to specify uncertainties in mass, inertial data, position of the centre of gravity, aerodynamic control power derivatives, stability derivatives, and some coefficients in the actuator and engine dynamics. In spite of these changes, the nominal models of HIRM+ and HIRM (i.e., with all uncertain parameters set to zero) are essentially the same.

Although variations of the uncertainty parameters affect the trim values of states and control surface deflections, due to the HIRM's fairly linear aerodynamic derivatives over the specified flight envelope, the stability properties remain essentially unchanged

Another aspect arising from the current industrial clearance practice is to allow the use of expected tolerance ranges of typical uncertain parameters (e.g., stability and control power derivatives) to be directly accessible in the nonlinear model. This allows the HIRM+ to mimic the industrial clearance approach, which is heavily based on both linear and nonlinear aircraft models. Usually, individual entries of the state-space matrices, with known physical meaning, are considered as uncertain and varied within the expected ranges. 


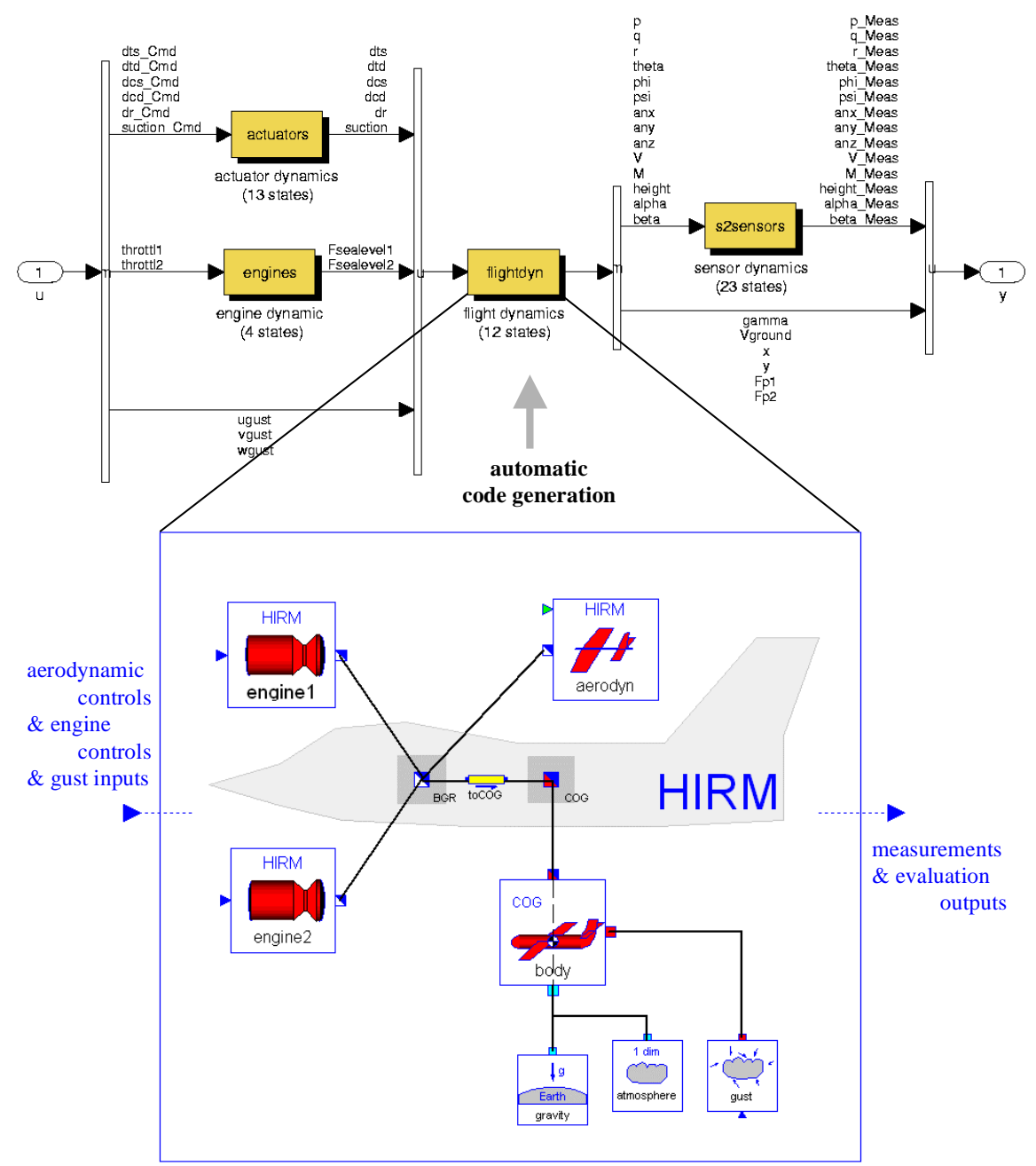

Fig. 8.2. The HIRM+ aircraft dynamics model

\subsection{The HIRM+ Object Model}

The HIRM+ aircraft dynamics model in the upper part of Figure 8.2 consists of four basic blocks denoted as: actuator dynamics, engine dynamics, flight dynamics and sensor dynamics. Zooming into the flight dynamics model displays its internal structure, as given in the lower half of Fig. 8.2: The flight dynamics block incorporates the mass properties including equations of motion and the models of aerodynamics, variations in thrust, gravity, atmosphere, and gust disturbances $[2,3]$. 
In contrast to the (input-output) block-oriented description of the aircraft dynamics model, the flight dynamics model itself is specified using an acausal model formulation [4]. Due to the acausal approach, interconnections between components are not limited to signal flows but represent physical system interactions, like energy flows, or kinematic constraints. Automatic code generation is used to import the flight dynamics into the overall model.

The outputs of the flight dynamics model, which are used as measurements for control and evaluation outputs are specified in Table 8.1.

Table 8.1. Measurements and evaluation outputs of HIRM+

\begin{tabular}{|c|c|c|c|}
\hline \multicolumn{2}{|l|}{ Name } & Description & Unit \\
\hline \multicolumn{4}{|c|}{ measurements } \\
\hline$p$ & $\mathrm{y}(1)$ & Body-axis roll rate & $\mathrm{rad} / \mathrm{s}$ \\
\hline$q$ & $\mathrm{y}(2)$ & Body-axis pitch rate & $\mathrm{rad} / \mathrm{s}$ \\
\hline$r$ & $\mathrm{y}(3)$ & Body-axis yaw rate & $\mathrm{rad} / \mathrm{s}$ \\
\hline$\theta$ & $\mathrm{y}(4)$ & Pitch angle & $\mathrm{rad}$ \\
\hline$\phi$ & $\mathrm{y}(5)$ & Bank angle & $\mathrm{rad}$ \\
\hline$\psi$ & $\mathrm{y}(6)$ & Heading angle & $\mathrm{rad}$ \\
\hline$a_{x}$ & $\mathrm{y}(7)$ & Body-axis $\mathrm{x}$-acceleration & $\mathrm{m} / \mathrm{s}^{2}$ \\
\hline$a_{y}$ & $y(8)$ & Body-axis y-acceleration & $\mathrm{m} / \mathrm{s}^{2}$ \\
\hline$a_{z}$ & $\mathrm{y}(9)$ & Body-axis z-acceleration & $\mathrm{m} / \mathrm{s}^{2}$ \\
\hline$V_{A}$ & $\mathrm{y}(10)$ & Airspeed & $\mathrm{m} / \mathrm{s}$ \\
\hline$M$ & $\mathrm{y}(11)$ & Mach number & - \\
\hline$h$ & $\mathrm{y}(12)$ & Altitude & $\mathrm{m}$ \\
\hline$\alpha$ & $\mathrm{y}(13)$ & Angle of attack & $\mathrm{rad}$ \\
\hline$\beta$ & $\mathrm{y}(14)$ & Angle of sideslip & $\mathrm{rad}$ \\
\hline \multicolumn{4}{|c|}{ evaluation } \\
\hline$\gamma$ & $\mathrm{y}(15)$ & Flight path angle & $\mathrm{rad}$ \\
\hline$V_{G}$ & $\mathrm{y}(16)$ & Ground speed (magnitude) & $\mathrm{m} / \mathrm{s}$ \\
\hline$x$ & $\mathrm{y}(17)$ & Earth-axes x-position (north) & $\mathrm{m}$ \\
\hline$y$ & $\mathrm{y}(18)$ & Earth-axes y-position (east) & $\mathrm{m}$ \\
\hline$F_{p 1}$ & $\mathrm{y}(19)$ & Thrust of engine 1 (left engine) & $\mathrm{N}$ \\
\hline$F_{p 2}$ & $\mathrm{y}(19)$ & Thrust of engine 2 (right engine) & $\mathrm{N}$ \\
\hline
\end{tabular}

The inputs of the aircraft dynamics model (aerodynamic controls, engine controls, and gust inputs) are specified in Table 8.2. 
Table 8.2. Controls and gust inputs of HIRM+

\begin{tabular}{cclc}
\hline Name & & Description & Unit \\
\hline$\delta_{T S}$ & $\mathrm{u}(1)$ & Symmetric tailplane deflection & $\mathrm{rad}$ \\
$\delta_{T D}$ & $\mathrm{u}(2)$ & Differential tailplane deflection & $\mathrm{rad}$ \\
$\delta_{C S}$ & $\mathrm{u}(3)$ & Symmetric canard deflection & $\mathrm{rad}$ \\
$\delta_{C D}$ & $\mathrm{u}(4)$ & Differential canard deflection & $\mathrm{rad}$ \\
$\delta_{R}$ & $\mathrm{u}(5)$ & Rudder deflection & $\mathrm{rad}$ \\
suction & $\mathrm{u}(6)$ & Nose suction & - \\
$\delta_{T H_{1}}$ & $\mathrm{u}(7)$ & Throttle of engine 1 (left engine) & - \\
$\delta_{T H_{2}}$ & $\mathrm{u}(8)$ & Throttle of engine 2 (right engine) & - \\
$W_{X_{B}}$ & $\mathrm{u}(9)$ & Body-axes head wind & $\mathrm{m} / \mathrm{s}$ \\
$W_{Y_{B}}$ & $\mathrm{u}(10)$ & Body-axes cross wind & $\mathrm{m} / \mathrm{s}$ \\
$W_{Z_{B}}$ & $\mathrm{u}(11)$ & Body-axes vertical wind & $\mathrm{m} / \mathrm{s}$ \\
\hline & & &
\end{tabular}

The uncertain parameters of the HIRM+, their formulation, nominal values, upper and lower bounds, units and descriptions are given in sections 8.2.1 to 8.2.5.

\subsubsection{Mass characteristics and geometric data}

The body-object of Fig. 8.2 specifies the mass characteristics and the rigid body differential equations of motion with 6 degrees of freedom. For a derivation of these equations a reference such as [5] should be consulted.

The HIRM+ mass characteristics are specified in Table 8.3

Variations in mass and moment of inertia are given by the following equations. For convenience, the uncertain parameters of the HIRM+ are denoted with an asterisk and parameters without, as their nominal values. The uncertainty itself is expressed by the subscript $U n c$ :

$$
\begin{gathered}
m^{*}=\left(m_{U n c}+1\right) m \\
I^{*}=\left[\begin{array}{ccc}
I_{x}\left(1+I_{x_{U n c}}\right) & 0 & -I_{x z}\left(1+I_{x z_{U n c}}\right) \\
0 & I_{y}\left(1+I_{y_{U n c}}\right) & 0 \\
I_{x z}\left(1+I_{x z_{U n c}}\right) & 0 & I_{z}\left(1+I_{z_{U n c}}\right)
\end{array}\right]
\end{gathered}
$$

The centre of gravity varies with respect to its nominal value which is defined as body geometric reference BGR, see Fig. 8.2):

$$
\begin{gathered}
X_{c g}^{*}=X_{c g}+X_{c g_{U n c}} \\
Y_{c g}^{*}=Y_{c g}+Y_{c g_{U n c}} \\
Z_{c g}^{*}=Z_{c g}+Z_{c g_{U n c}}
\end{gathered}
$$


Table 8.3. Inertial parameters

\begin{tabular}{crcl}
\hline Name & Nominal value & Unit & Description \\
\hline$m$ & 15296.0 & $\mathrm{~kg}$ & Aircraft total mass \\
$I_{x}$ & 24549.0 & $\mathrm{~kg} \mathrm{~m}^{2}$ & x body moment of inertia \\
$I_{y}$ & 163280.0 & $\mathrm{~kg} \mathrm{~m}^{2}$ & y body axis moment of inertia \\
$I_{z}$ & 183110.0 & $\mathrm{~kg} \mathrm{~m}^{2}$ & z body moment of inertia \\
$I_{x z}$ & -3124.0 & $\mathrm{~kg} \mathrm{~m}^{2}$ & x-z body axis product of inertia \\
$X_{c g}$ & 0 & $\mathrm{~m}$ & Centre of gravity location along $x$-axis \\
& & & w.r.t. body geometric reference BGR \\
$Y_{c g}$ & 0 & Centre of gravity location along $y$-axis \\
& & & w.r.t. body geometric reference BGR \\
$Z_{c g}$ & 0 & $\mathrm{~m}$ & Centre of gravity location along $z$-axis \\
& & & w.r.t. body geometric reference BGR \\
\hline
\end{tabular}

Table 8.4. Inertial uncertain parameters

\begin{tabular}{|c|c|c|c|c|}
\hline Name & $\begin{array}{c}\text { Nominal } \\
\text { value }\end{array}$ & {$[\min ; \max ]$} & Unit & Description \\
\hline$m_{U n c}$ & 0 & {$[-0.2 ; 0.2]$} & - & Uncertainty level of aircraft mass \\
\hline$X_{c g_{U n c}}$ & 0 & {$[-0.15 ; 0.15]$} & $\mathrm{m}$ & $\begin{array}{l}\text { Centre of Gravity offset along } \\
\text { x-axis from nominal } X_{c g} \text {, positive } \\
\text { toward nose }\end{array}$ \\
\hline$Y_{c g_{U n c}}$ & 0 & {$[-0.10 ; 0.10]$} & $\mathrm{m}$ & $\begin{array}{l}\text { Centre of Gravity offset along } \\
\text { y-axis from nominal } Y_{c g} \text {, positive } \\
\text { toward starboard }\end{array}$ \\
\hline$Z_{c g_{U n c}}$ & 0 & {$[-0.04 ; 0.04]$} & $\mathrm{m}$ & $\begin{array}{l}\text { Centre of Gravity offset along } \\
\text { z-axis from nominal } Z_{c g} \text {, positive } \\
\text { down }\end{array}$ \\
\hline$I_{x_{U n c}}$ & 0 & {$[-0.2 ; 0.2]$} & - & Uncertainty level of $I_{x}$ \\
\hline$I_{y_{U n c}}$ & 0 & {$[-0.05 ; 0.05]$} & - & Uncertainty level of $I_{y}$ \\
\hline$I_{z_{U n c}}$ & 0 & {$[-0.08 ; 0.08]$} & - & Uncertainty level of $I_{z}$ \\
\hline$I_{x z_{U n c}}$ & 0 & {$[-0.2 ; 0.2]$} & - & Uncertainty level of $I_{x z}$ \\
\hline
\end{tabular}

The parametric uncertainties in the HIRM+ mass characteristics are defined using the parameters given in Table 8.4 in terms of their nominal values (see Table 8.3) and their set of uncertain parameters. 
In some cases (e.g. mass) physical units are not shown, because the uncertainties are expressed in terms of percentages ( $\pm 20 \%$ for mass) of the nominal value.

\subsubsection{Aerodynamics}

The aerodyn-object of Fig. 8.2 describes the aerodynamic forces and moments. The aerodynamic force and moment coefficients for HIRM+ are given by the summation of several components [1]. Most components have the form $C_{a_{b}}(c, d)$. The derivative for a force or a moment $a$ with respect to $b$ is determined by linearly interpolating between the values given in a look-up table as a function of the variables $c$ and $d$.

The basic aerodynamic parameters are specified in Table 8.5

Table 8.5. Aerodynamic parameters

\begin{tabular}{cccl}
\hline Name & Nominal value & Unit & Description \\
\hline $\bar{c}$ & 3.511 & $\mathrm{~m}$ & Mean aerodynamic chord \\
$S$ & 37.16 & $\mathrm{~m}^{2}$ & Wing planform area \\
$b$ & 11.4 & $\mathrm{~m}$ & Wingspan \\
\hline
\end{tabular}

To allow a physically meaningful interpretation of parametric variations with a direct influence on the stability and control power derivatives, the uncertain parameters in the HIRM+ have been defined such that they can be directly recovered in the linearised models. This has the undesired effect that trim values are explicitly used in the definition of uncertain parameters, which means, that the nonlinear simulations are now trim point dependent through initial state components (e.g., $\alpha_{\text {trim }}$ ) and initial control surfaces (e.g., $\left.\delta_{C S_{\text {trim }}}\right)$. Thus, strictly speaking, even for the nonlinear model this approach permits only small manoeuvres close to the trim point. This approach is convenient, in that it allows model upgrades to be made at the level of the nonlinear model, prior to linearisation. In what follows the expressions of the uncertain aerodynamic moment coefficients are given, where trim values of various parameters are specified with the subscript trim (e.g., $\left.\alpha_{\text {trim }}\right)$.

Uncertain pitching moment coefficient:

$$
\begin{aligned}
C_{m}^{*}= & C_{m}+C_{m_{0 U n c}}+C_{m_{\delta C S U n c}}\left(\delta_{C S}-\delta_{C S_{t r i m}}\right) \\
& +C_{m_{\delta T S U n c}}\left(\delta_{T S}-\delta_{T S_{t r i m}}\right)+C_{m_{\alpha U n c}}\left(\alpha-\alpha_{t r i m}\right) \\
& +C_{m_{q U n c}}\left(q-q_{t r i m}\right) \frac{\bar{c}}{2} V_{A}
\end{aligned}
$$

with $C_{m}$ as the nominal pitching moment coefficient of HIRM, depending on $\delta_{T S}, \delta_{C S}$, etc. 
Uncertain rolling moment coefficient:

$$
\begin{aligned}
C_{l}^{*}= & C_{l}+C_{l_{0} U n c}+C_{l_{\delta C D U n c}}\left(\delta_{C D}-\delta_{C D_{t r i m}}\right) \\
& +C_{l_{\delta T D U n c}}\left(\delta_{T D}-\delta_{T D_{t r i m}}\right)+C_{l_{\delta R U n c}}\left(\delta_{R}-\delta_{R_{t r i m}}\right) \\
& +C_{l_{\beta U n c}}\left(\beta-\beta_{t r i m}\right)+C_{l_{r U n c}} r \frac{b}{2 V_{A}}+C_{l_{p U n c}} p \frac{b}{2 V_{A}}
\end{aligned}
$$

with $C_{l}$ as the nominal rolling moment coefficient of HIRM.

Uncertain yawing moment coefficient:

$$
\begin{aligned}
C_{n}^{*} & =C_{n}+C_{n_{0 U n c}}+C_{n_{\delta C D U n c}}\left(\delta_{C D}-\delta_{C D_{t r i m}}\right) \\
& +C_{n_{\delta T D U n c}}\left(\delta_{T D}-\delta_{T D_{t r i m}}\right)+C_{n_{\delta R U n c}}\left(\delta_{R}-\delta_{R_{t r i m}}\right) \\
& +C_{n_{\beta U n c}}\left(\beta-\beta_{t r i m}\right)+C_{n_{r U n c}} r \frac{b}{2 V_{A}}+C_{n_{p U n c}} p \frac{b}{2 V_{A}}
\end{aligned}
$$

\begin{tabular}{|c|c|c|c|c|}
\hline Name & $\begin{array}{l}\text { Nom. } \\
\text { value }\end{array}$ & {$[\min ; \max ]$} & Unit & Description \\
\hline$C_{l_{0 U n c}}$ & 0 & {$[0 ; 0]$} & - & Uncertainty in rolling moment \\
\hline$C_{m_{0 U n c}}$ & 0 & {$[0 ; 0]$} & - & Uncertainty in pitching moment \\
\hline$C_{n_{0 U n c}}$ & 0 & {$[0 ; 0]$} & - & Uncertainty in yawing moment \\
\hline$C_{m_{\alpha U n c}}$ & 0 & {$[-0.1 ; 0.1]$} & $1 / \mathrm{rad}$ & Uncertainty in $C_{m \alpha}$ stability derivative \\
\hline$C_{l_{\beta U n c}}$ & 0 & {$[-0.04 ; 0.04]$} & $1 / \mathrm{rad}$ & $\begin{array}{l}\text { Uncertainty in } C_{l \beta} \text { stability derivative, } \\
\text { where: } \mathrm{k}=1 \text { for } \alpha<12^{\circ}, \mathrm{k}=2 \text { for } \\
\alpha>20^{\circ} \text {, and } \mathrm{k} \text { is linearly interpolated } \\
\text { for } 12^{\circ} \leq \alpha \leq 20^{\circ} \text { between } 1 \text { and } 2 \text {. }\end{array}$ \\
\hline$C_{n_{\beta U n c}}$ & 0 & {$[-0.04 ; 0.04]$} & $1 / \mathrm{rad}$ & Uncertainty in $C_{n \beta}$ stability derivative \\
\hline$C_{m_{q U n c}}$ & 0 & {$[-0.1 ; 0.1]$} & - & $\begin{array}{l}\text { Uncertainty in pitching moment deriva- } \\
\text { tive due to normalised pitch rate }\end{array}$ \\
\hline$C_{l_{p U n c}}$ & 0 & {$[-0.1 ; 0.1]$} & - & $\begin{array}{l}\text { Uncertainty in rolling moment deriva- } \\
\text { tive due to normalised roll rate }\end{array}$ \\
\hline$C_{l_{r U n c}}$ & 0 & {$[-0.03 ; 0.03]$} & - & $\begin{array}{l}\text { Uncertainty in rolling moment deriva- } \\
\text { tive due to normalised yaw rate }\end{array}$ \\
\hline$C_{n_{p U n c}}$ & 0 & {$[-0.1 ; 0.1]$} & - & $\begin{array}{l}\text { Uncertainty in yawing moment deriva- } \\
\text { tive due to normalised roll rate }\end{array}$ \\
\hline$C_{n_{r U n c}}$ & 0 & {$[-0.05 ; 0.05]$} & - & $\begin{array}{l}\text { Uncertainty in yawing moment deriva- } \\
\text { tive due to normalised yaw rate }\end{array}$ \\
\hline
\end{tabular}

with $C_{n}$ as the nominal yawing moment coefficient of HIRM.

Table 8.6. Uncertain parameters of aerodynamic stability derivatives

In Tables 8.6 and 8.7 the ranges of the uncertain aerodynamic stability derivatives and control power derivatives are given. For some parameters, no 
value of uncertainty has been defined. These terms have been included to allow for future applications of the model.

Table 8.7. Uncertain parameters of aerodynamic control power derivatives

\begin{tabular}{|c|c|c|c|c|}
\hline Name & $\begin{array}{l}\text { Nom. } \\
\text { value }\end{array}$ & {$[\min ; \max ]$} & Unit & Description \\
\hline$C_{m_{\delta T S U n c}}$ & c 0 & {$[-0.04 ; 0.04]$} & $1 / \mathrm{rad}$ & $\begin{array}{l}\text { Uncertainty in pitching moment } \\
\text { derivative due to symmetrical } \\
\text { tailplane deflection }\end{array}$ \\
\hline$C_{m_{\delta C S U n c}}$ & ${ }_{c} 0$ & {$[-0.02 ; 0.02]$} & $1 / \mathrm{rad}$ & $\begin{array}{l}\text { Unc. in pitching moment derivative } \\
\text { due to symmetrical canard deflection }\end{array}$ \\
\hline$C_{l_{\delta T D U n c}}$ & 0 & {$[-0.04 ; 0.04]$} & $1 / \mathrm{rad}$ & $\begin{array}{l}\text { Unc. in rolling moment derivative } \\
\text { due to differential tailplane deflection }\end{array}$ \\
\hline$C_{l_{\delta C D U n c}}$ & 0 & {$[-0.02 ; 0.02]$} & $1 / \mathrm{rad}$ & $\begin{array}{l}\text { Unc. in rolling moment derivative } \\
\text { due to differential canard deflection }\end{array}$ \\
\hline$C_{l_{\delta R U n c}}$ & 0 & {$[-0.006 ; 0.006]$} & $1 / \mathrm{rad}$ & $\begin{array}{l}\text { Uncertainty in rolling moment deri- } \\
\text { vative due to rudder deflection }\end{array}$ \\
\hline$C_{n_{\delta T D U n c}}$ & 0 & {$[-0.02 ; 0.02]$} & $1 / \mathrm{rad}$ & $\begin{array}{l}\text { Unc. in yawing moment derivative } \\
\text { due to differential tailplane deflection }\end{array}$ \\
\hline$C_{n_{\delta C D U n c}}$ & 0 & {$[-0.01 ; 0.01]$} & $1 / \mathrm{rad}$ & $\begin{array}{l}\text { Unc. in yawing moment derivative } \\
\text { due to differential canard deflection }\end{array}$ \\
\hline$C_{n_{\delta R U n c}}$ & 0 & {$[-0.02 ; 0.02]$} & $1 / \mathrm{rad}$ & $\begin{array}{l}\text { Uncertainty in yawing moment deri- } \\
\text { vative due to rudder deflection }\end{array}$ \\
\hline
\end{tabular}

\subsubsection{Engine dynamics}

Each engine-object of Fig. 8.2 is modelled as shown in Fig. 8.3. A throttle

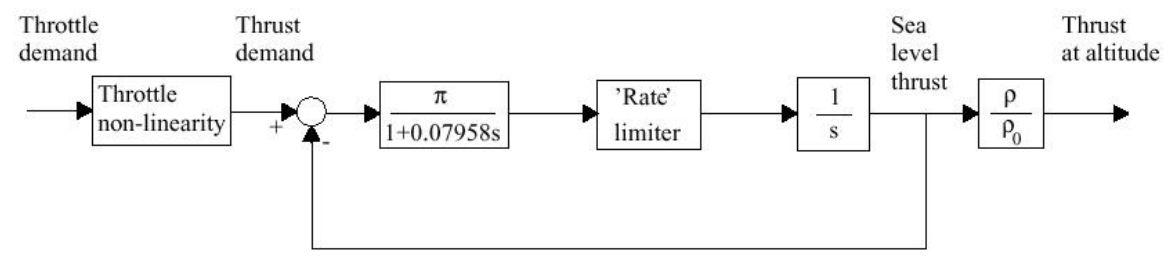

Fig. 8.3. Engine dynamics model

demand of 0 selects idle which is $10 \mathrm{kN}$ of thrust at sea level. A throttle demand of 1 corresponds to maximum dry thrust of $47 \mathrm{kN}$. Full reheat is selected when the throttle demand equals 2 and corresponds to a thrust 
of $72 \mathrm{kN}$. The rate at which the thrust changes depends on whether the engine is in dry thrust or reheat. For dry thrust, the maximum rate of change is 12 $\mathrm{kN} / \mathrm{s}$ whereas in reheat it is $25 \mathrm{kN} / \mathrm{s}$. The sea level engine thrust is scaled with the relation of local density $\rho$ to sea level density $\rho_{0}$.

The engine setting angles are zero and so the thrust acts parallel to aircraft $\mathrm{x}$-body axis. The engine positions with respect to the body geometric reference BGR are given in Table 8.8.

Table 8.8. Engine parameters

\begin{tabular}{lrrl}
\hline Name & $\begin{array}{r}\text { Nom. } \\
\text { value }\end{array}$ & Unit & Description \\
\hline$X_{T A P}$ & -6.0 & $\mathrm{~m}$ & Body-axes x-position of thrust application point \\
$Y_{T A P}$ & \pm 0.56 & $\mathrm{~m}$ & Body-axes y-position of thrust application point \\
$Z_{T A P}$ & 0.35 & $\mathrm{~m}$ & Body-axes z-position of thrust application point \\
$t h r_{\text {idle }}$ & 10000 & $\mathrm{~N}$ & Idle thrust (at sea level) \\
$t h r_{\text {drymax }_{\text {max }}}$ & 47000 & $\mathrm{~N}$ & Maximum dry thrust (at sea level) \\
$t h r_{\text {reheat }_{\text {max }}}$ & 72000 & $\mathrm{~N}$ & Maximum reheat thrust (at sea level) \\
$t h r_{\text {dry }_{r L}}$ & \pm 12000 & $\mathrm{~N} / \mathrm{s}$ & Ratelimit at dry thrust \\
$t h r_{\text {reheat }_{r L}}$ & \pm 25000 & $\mathrm{~N} / \mathrm{s}$ & Ratelimit at reheat thrust \\
\hline
\end{tabular}

Variations due to parametric uncertainties in engine rate limiters for dry thrust and reheat thrust are given by the following equations:

$$
\begin{aligned}
& t h r_{d r y_{r L}}{ }^{*}=t h r_{d r y_{r L}}\left(1+\operatorname{Eng}_{r L_{U n c}}\right) \\
& \operatorname{thr}_{\text {reheat }_{r L}}{ }^{*}=t h r_{\text {reheat }}\left(1+\operatorname{Eng}_{r L_{U n c}}\right)
\end{aligned}
$$

The uncertainty level of the engine rate limits is given in Table 8.9.

Table 8.9. Engine uncertain parameter

\begin{tabular}{lcccl}
\hline Name & $\begin{array}{c}\text { Nominal } \\
\text { value }\end{array}$ & $\begin{array}{r}{[\min ;} \\
\max ]\end{array}$ & Unit & Description \\
\hline Eng $_{r L_{U n c}}$ & 0 & {$[0 ; 0]$} & - & Uncertainty level of engine rate limits \\
\hline
\end{tabular}

\subsubsection{Actuator dynamics}

The actuator dynamics block of Fig. 8.2 is specified by the following transfer functions: 
Taileron actuator transfer function:

$$
T^{*}(s)=\frac{1}{\left(1+0.026\left(1+\delta_{T_{b w U n c}}\right) s\right)\left(1+0.007692 s+0.00005917 s^{2}\right)}
$$

with an uncertain rate limit defined as $\pm 80\left(1+\delta_{T_{r L U n c}}\right)^{\circ} / \mathrm{s}$

Canard actuator transfer function:

$$
T^{*}(s)=\frac{1}{\left(1+0.0157333\left(1+\delta_{C_{b w U n c}}\right) s+0.00017778 s^{2}\right)}
$$

with an uncertain rate limit defined as $\pm 80\left(1+\delta_{C_{r L U n c}}\right)^{\circ} / \mathrm{s}$

Rudder actuator transfer function:

$$
T^{*}(s)=\frac{1}{\left(1+0.0191401\left(1+\delta_{R_{b w U n c}}\right) s+0.000192367 s^{2}\right)}
$$

with an uncertain rate limit defined as $\pm 80\left(1+\delta_{R_{r L U n c}}\right)^{\circ} / \mathrm{s}$

For the actuator dynamics block, currently no values of uncertainty has been defined. These terms have been included for future applications of the model.

Table 8.10. Actuation uncertain parameters

\begin{tabular}{lcccl}
\hline Name & $\begin{array}{c}\text { Nom. } \\
\text { value }\end{array}$ & $\begin{array}{r}{[\mathrm{min} ;} \\
\max ]\end{array}$ & Unit & Description \\
\hline$\delta_{T_{r L U n c}}$ & 0 & {$[0 ; 0]$} & - & Uncertainty level of tailplane rate limit \\
$\delta_{T_{b w U n c}}$ & 0 & {$[0 ; 0]$} & - & Uncertainty level of tailplane bandwidth \\
$\delta_{C_{r L U n c}}$ & 0 & {$[0 ; 0]$} & - & Uncertainty level of canard rate limit \\
$\delta_{C_{b w U n c}}$ & 0 & {$[0 ; 0]$} & - & Uncertainty level of canard bandwidth \\
$\delta_{R_{r L U n c}}$ & 0 & {$[0 ; 0]$} & - & Uncertainty level of rudder rate limit \\
$\delta_{R_{b w U n c}}$ & 0 & {$[0 ; 0]$} & - & Uncertainty level of rudder bandwidth \\
\hline
\end{tabular}

\subsubsection{Sensor dynamics}

To reduce the complexity of the overall model, and thus the computation times required by simulations, the sensor dynamics for HIRM are replaced by lower order approximated sensor models for the HIRM+, described by transfer functions.

The HIRM+ sensor dynamics for body axis angular rates $[p, q, r]$ and body axis accelerations $\left[a_{x}, a_{y}, a_{z}\right]$ :

$$
T^{*}(s)=\frac{1-0.005346 s+0.0001903 s^{2}}{1+0.03082 s+0.0004942 s^{2}}
$$


The HIRM+ sensor dynamics for airspeed, Mach-number, altitude, angle of attack and angle of sideslip $\left[V_{A}, M a, h, \alpha, \beta\right]$ :

$$
T^{*}(s)=\frac{1}{1+0.02 s}
$$

The HIRM+ sensor dynamics for body axis attitudes and heading angle $[\varphi, \theta, \psi]:$

$$
T^{*}(s)=\frac{1}{1+0.0323 s+0.00104 s^{2}}
$$

A measurement error signal is added to the signal of $\alpha$ and $\beta$. These errors are assumed to be constant during the period of simulation:

$$
\begin{gathered}
\alpha *=\alpha+\alpha_{U n c} \\
\beta *=\beta+\beta_{U n c}
\end{gathered}
$$

For the HIRM+ sensor dynamics block, currently no value of uncertainty for $\alpha$ - and $\beta$-measurement errors have been defined. These terms have been included for compatibility with the HIRM, in which these uncertainties had been used.

Table 8.11. Sensor uncertain parameters

\begin{tabular}{ccccl}
\hline Name & nom & {$[$ min; max $]$} & Unit & Description \\
\hline$\alpha_{U n c}$ & 0 & {$[0 ; 0]$} & {$[\mathrm{rad}]$} & $\begin{array}{l}\text { Uncertainty in sensed angle of attack } \\
\text { (added to the } \alpha \text {-measurement signal) }\end{array}$ \\
$\beta_{U n c}$ & 0 & {$[0 ; 0]$} & {$[\mathrm{rad}]$} & $\begin{array}{l}\text { Uncertainty in sensed sideslip angle } \\
\text { (added to the } \beta \text {-measurement signal) }\end{array}$ \\
\hline
\end{tabular}

\subsection{Automated Model Generation for Parametric Time Simulations and Trim Computations}

The object model in Fig. 8.2 is graphically specified using components from the Flight Dynamics Library [3], that are instantiated with HIRM+ specific system model parameters. From this object model, simulation and analysis models of the aircraft system dynamics and documentation can be generated automatically (see Fig. 8.4).

In the mathematical model building process, the equation handler of DYMOLA solves the equations according to the inputs and outputs of the complete HIRM+ model. Equations that are formulated in an object, but that 


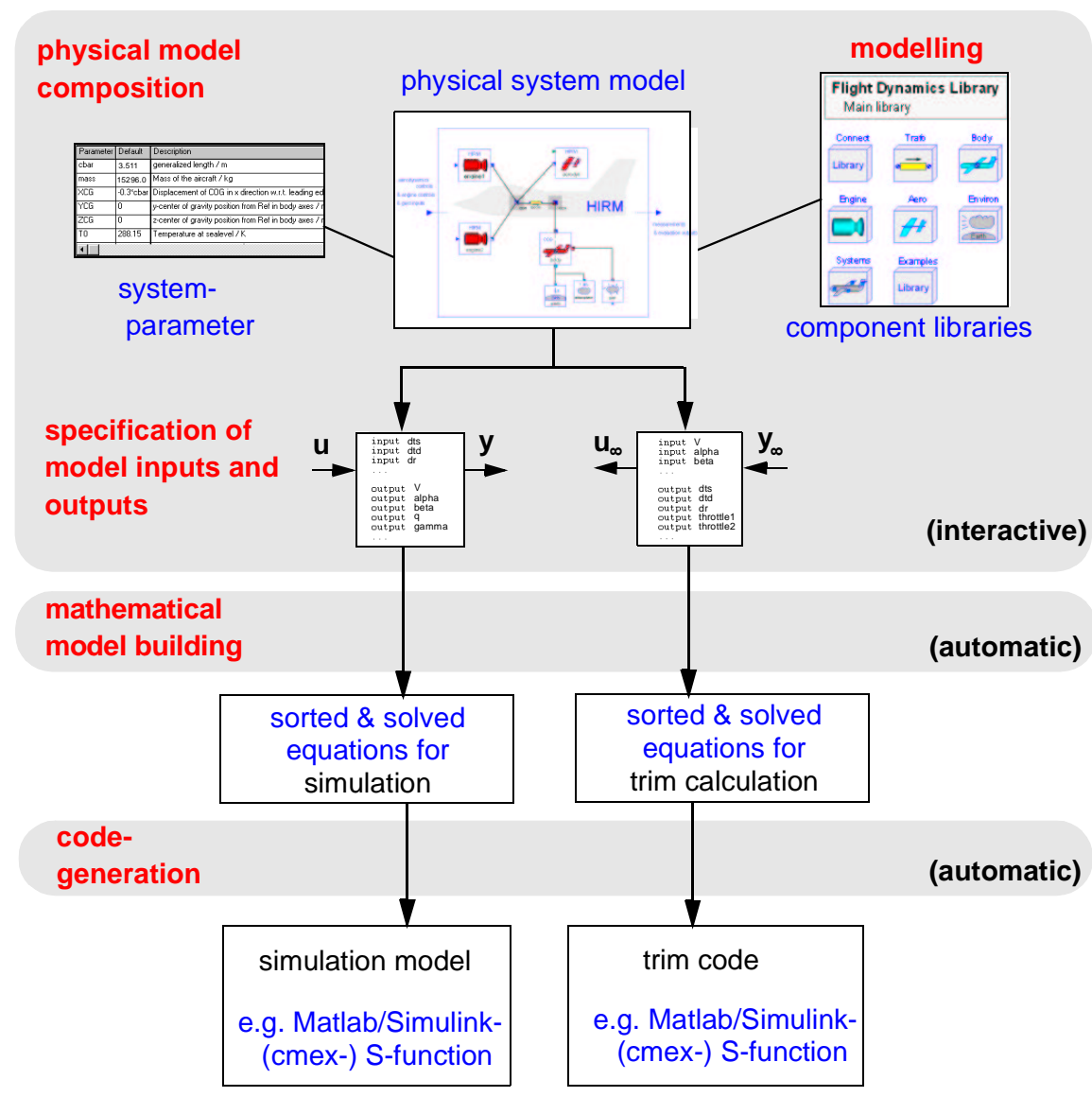

Fig. 8.4. Model building process

are superfluous for capturing the behaviour of the particular model, are automatically removed. The result is a nonlinear symbolic state-space description with a minimum number of equations for this task

$$
\begin{aligned}
& \dot{x}=f(x, u, p) \\
& y=h(x, u, p)
\end{aligned}
$$

From the symbolic description, numerical simulation code for different simulation environments is generated automatically. In this way, it is possible to generate, for example, a MATLAB-Simulink m-file or cmex-code, or CCode according to the neutral DSBLOCK standard [7], which can be used in any simulation environment, being capable of importing C-Code.

From the sorted and solved equations for simulation, symbolic analysis code can be generated, describing a parameterised state-space model. This 
code can be used to extract in an automated procedure the so-called Linear Fractional Transformation (LFT) standard form, that may serve as the basis for $\mu$ robustness analysis. A detailed description of the generation of an LFT representation from an object model as depicted in Fig. 8.4 can be found in $[8]$.

One of the key aspects of the successful usage of an optimisation-based clearance methodology is an efficient trimming approach. The trimming of HIRM+ is a very challenging computational task, involving the numerical solution of a system of 60 nonlinear equations for the stationary values of state and control variables appearing in the HIRM+ state model. The difficulties mainly arise because of the lack of differentiability of the functions due to the presence of various look-up tables used for linear interpolations. Severe nonlinearities in the engine model and in the aerodynamics, as well as the presence of control surface deflection limiters make the numerical solution of this high order system of equations very difficult.

To manage the trimming problem, an highly accurate and efficient approach has been employed in [2]. The facilities of an equation based modelling environment as Dymola [4] allows the generation of C-code for an inverse model to serve for trimming. Such a model has as inputs the desired trim conditions (such as $V_{a}, \alpha, \ldots$ ) and as outputs the corresponding equilibrium values of trimmed state $(x)$ and control vectors (such as $\left.\delta_{T S}, \delta_{C S}, \ldots\right)$. DYMOLA generates essentially explicit equations for the inverse model by trying to solve the $60^{\text {th }}$ order nonlinear equation symbolically. Even if a symbolic solution cannot be determined, Dymola is still able to reduce the burden of solving numerically a $60^{\text {th }}$ order system of nonlinear equations to the solution of a small core system of 13 nonlinear equations which ultimately must be solved numerically. Thus, the trimming procedure based on such an inverse model is very fast and very accurate.

\subsection{Flight Conditions and Envelope Limits}

The analysis of HIRM+ is restricted to the flight conditions defined in Table 8.12. Depending on the clearance problem, the equilibrium conditions in these

Table 8.12. Set of flight conditions for clearance analysis

\begin{tabular}{ccccccccc}
\hline FC No. & $F C_{1}$ & $F C_{2}$ & $F C_{3}$ & $F C_{4}$ & $F C_{5}$ & $F C_{6}$ & $F C_{7}$ & $F C_{8}$ \\
\hline $\mathrm{M}$ & 0.2 & 0.3 & 0.5 & 0.5 & 0.6 & 0.7 & 0.8 & 0.8 \\
\hline $\mathrm{h}[\mathrm{ft}]$ & 5,000 & 25,000 & 40,000 & 15,000 & 30,0000 & 20,000 & 5,000 & 40,000 \\
\hline
\end{tabular}

points are defined by the trimming conditions for straight and level flight for given $\gamma, M$ and $h$ or pull-up manoeuvres for given $\alpha, M$ and $h$. For the 
variation of the $\alpha$ the interval $\left[-15^{\circ}, 35^{\circ}\right]$ has been chosen, and for gridding a step size $\Delta \alpha=2^{\circ}$ has been suggested.

When several aerodynamic uncertainties are simultaneously used in the analysis, reduction factors must be applied on their absolute values as specified in Tables 8.6 and 8.7. The values of reduction factors for different numbers of aerodynamic uncertainties are given in Table 8.13.

Table 8.13. Reduction factors for simultaneous aerodynamic uncertainties

\begin{tabular}{lcccc}
\hline Number of aerodynamic uncertainties & 2 & 3 & 4 & $\geq 5$ \\
\hline Reduction factor & 0.62 & 0.46 & 0.37 & 0.31 \\
\hline
\end{tabular}

Due to load factor limitations (section 8.4.1) and control surface deflection limits (section 8.4.2) it is not possible to trim all flight conditions of Table 8.12 for all angles of attack between $-15^{\circ}$ and $35^{\circ}$. This is already true for the nominal model, for which all uncertainty parameters are set to zero. The number of not trimmable points in the flight envelope increases with more uncertainty parameters being used. This fact must be accounted for during the assessment.

\subsubsection{Load factor limits}

The clearance task is restricted to a "true" flight envelope, where additional restrictions on variables must be satisfied. The first condition is to restrict the load factor to meet

$$
-3[g] \leq n_{z} \leq 7[g]
$$

All flight conditions, where this condition is violated can not be cleared. A preliminary check involving only nominal cases has been performed.

In Fig. 8.5 the values of load factors versus $\alpha$ for the eight flight conditions are presented. It can be seen that, because of violation of load-factor limit, $F C_{6}$ is defined only for $\alpha \in\left[-9^{\circ}, 29^{\circ}\right]$ and $F C_{7}$ is defined only for $\alpha \in$ $\left[-2^{\circ}, 12^{\circ}\right]$.

It is helpful to have the dependence of $n_{z}$ on various parameters in mind. In general, $n_{z}$ can be expressed as

$$
n_{z}=-\frac{\rho}{2 m g} V_{A}^{2} S C_{Z}
$$

and thus depends on the $Z$-force aerodynamic coefficient $C_{Z}$, altitude (via air density $\rho$ ), airspeed $V_{A}$, and mass of the aircraft $m$. For HIRM,$+ C_{Z}$ is given by $[1]$

$$
C_{Z}=C_{Z_{\delta_{T S}}}\left(\alpha, \delta_{T S}\right)+C_{Z_{\delta_{C S}}}\left(\alpha, \delta_{T S}\right) \delta_{C S}+1.7555 C_{Z_{q}}\left(\alpha, \delta_{C S}\right) \frac{q}{V_{A}}
$$




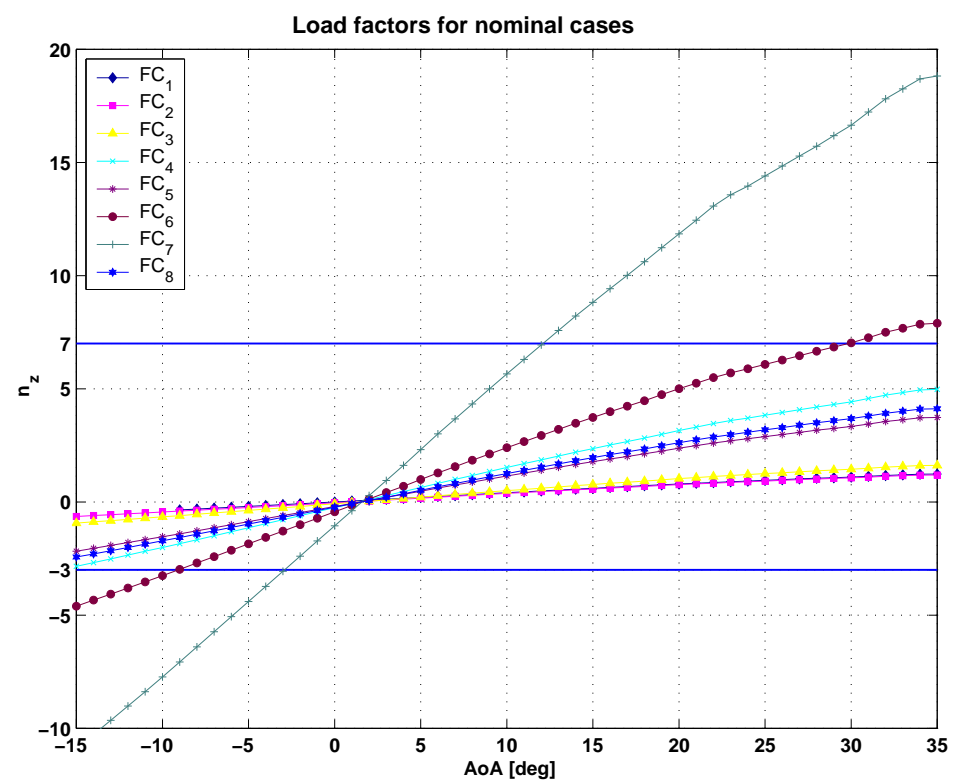

Fig. 8.5. Nominal load factors for HIRM+

Because $\delta_{C S}=0^{\circ}$ (the canards are not used) and the term $1.7555 C_{Z_{q}}\left(\alpha, \delta_{C S}\right) \frac{q}{V_{A}}$ being much smaller than $C_{Z_{\delta_{T S}}}, C_{Z}$ can be approximated by the single term $C_{Z} \approx C_{Z_{\delta_{T S}}}\left(\alpha, \delta_{T S}\right)$, where the dependence on $\delta_{T S}$, being not significant, can be dropped. Thus, if we neglect the pitching motion, $n_{z}$ for straight and level flight can be expressed as

$$
n_{z} \approx-\frac{\rho}{2 m g} V_{A}^{2} S C_{Z_{\delta_{T S}}}(\alpha)
$$

and depends finally only on $\alpha$, altitude (influence on air density), the airspeed, and the mass of the aircraft. The uncertain parameters, with exception of the mass, do not have any influence on the values of $n_{z}$. A remarkable property of HIRM+ is that, independently of any values of uncertain model parameters, $n_{z} \approx 0$ for $\alpha$ close to $2^{\circ}$, because $C_{Z_{\delta_{T S}}}\left(2^{\circ}\right) \approx 0$. This particular feature of HIRM+ can be observed in Fig. 8.5.

\subsubsection{Control surface deflection limits}

A second set of conditions originate from the deflection limits on taileron and rudder actuators: 


$$
\begin{aligned}
& -40^{\circ} \leq \delta_{T S}+\delta_{T D} \leq 10^{\circ} \\
& -40^{\circ} \leq \delta_{T S}-\delta_{T D} \leq 10^{\circ} \\
& -30^{\circ} \leq \quad \delta_{R} \leq 30^{\circ}
\end{aligned}
$$

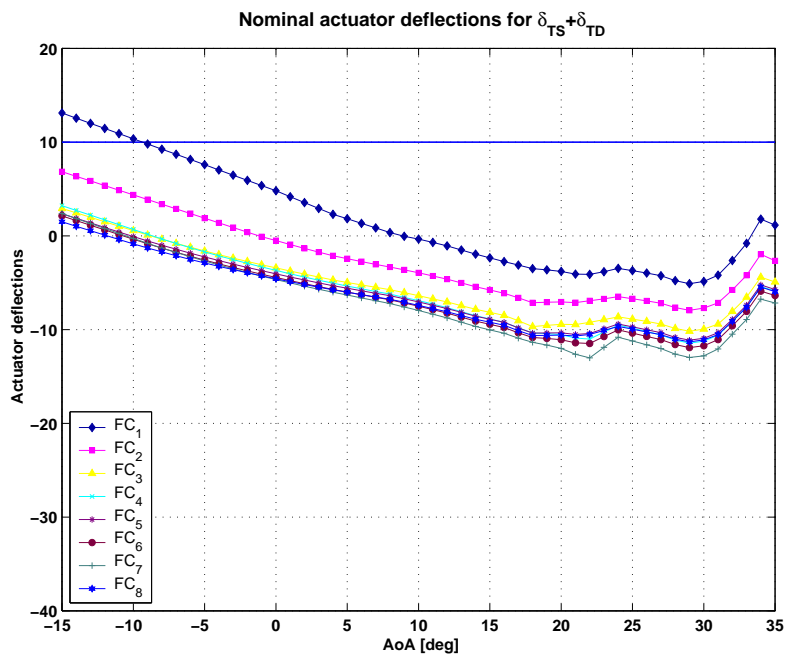

Fig. 8.6. Summation of symmetrical and differential tailplane deflection

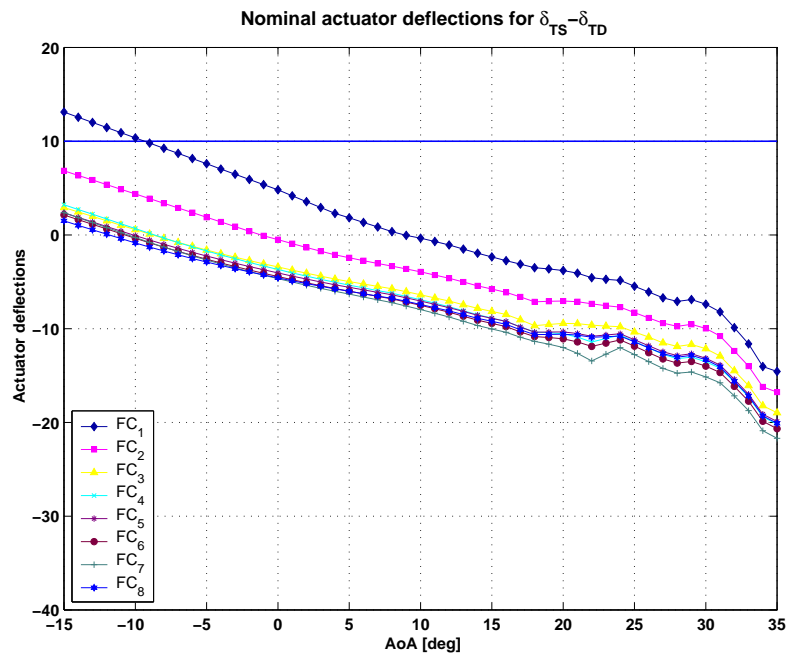

Fig. 8.7. Difference between symmetrical and differential tailplane deflection 
All flight conditions, where the above conditions are violated, lead to saturation of control surfaces, and thus are automatically not cleared. For the nominal cases, the variations of $\delta_{T S}+\delta_{T D}$ and $\delta_{T S}-\delta_{T D}$ for the rigid body equations of HIRM+ can be seen in Figures 8.6 and $8.7^{1}$. The values computed in these figures have been determined with the inverse trim routine where these limits are not present, and therefore the trimming is always possible. This is intentionally done, in order to make trimming numerically easier and to be able to study points also slightly outside of the limits for the control surface actuators. It follows that the trimming results are valid only if the above bounds are fulfilled. As a practical consequence, the above conditions must be checked after each trim computation. Ignoring these conditions leads to strange (but expected) effects, as for example, zero columns in the input matrix $B$ of the linearised HIRM+ in $F C_{1}$ for $\alpha \in\left[-15^{\circ},-10^{\circ}\right]$ because of saturation of inputs. This further leads to identically zero transfer function, when breaking the symmetric taileron loop.

According to these plots, for the nominal parameters, $F C_{1}$ is defined only for $\alpha \in\left[-9^{\circ}, 35^{\circ}\right]$ because of violation for $\alpha \in\left[-15^{\circ},-10^{\circ}\right]$ of the conditions $\delta_{T S} \pm \delta_{T D} \leq 10^{\circ}$. The variation of $\delta_{R}$ is within the allowed limits and is not shown here. Based on nominal case analysis results, the "true" set of flight conditions to serve for analysis purposes must be restricted.

\section{References}

1. Ewan Muir. The HIRM design challenge problem description. In J. F. Magni, S. Bennani and J. Terlouw, editors, Robust Flight Control, A Design Challenge, Lecture Notes in Control and Information Sciences, vol. 224, pp. 419-443, Springer Verlag, Berlin, 1997.

2. D. Moormann. Automatisierte Modellbildung der Flugsystemdynamik (Automated Modeling of Flight-System Dynamics). Dissertation, RWTH Aachen. VDI Fortschrittsberichte, Mess-, Steuerungs- und Regelungstechnik, Reihe 8, Nr. 931, ISBN: 3-18-393108-7, 2002.

3. D. Moormann and G. Looye. The Modelica Flight Dynamics Library. Modelica 2002, Proceedings of the 2nd International Modelica Conference. Oberpfaffenhofen, Germany, March 18-19, 2002.

4. H. Elmqvist. Object-Oriented Modeling and Automatic Formula Manipulation in Dymola. In Scandinavian Simulation Society SIMS'93, Kongsberg, Norway, June 1993.

5. R. Brockhaus. Flugregelung. Springer Verlag, Berlin, 1994.

6. J. F. Magni, S. Bennani and J. Terlouw. Robust Flight Control, A Design Challenge. Lecture Notes in Control and Information Sciences, vol. 224, Springer Verlag, Berlin, 1997.

7. M. Otter and H. Elmqvist. The DSblock Model Interface for Exchanging Model Components. Simulation, 71:7-22, 1998.

\footnotetext{
${ }^{1}$ Figures 8.6 and 8.7 are the same for $\alpha \leq 20^{\circ}$, because $\delta_{T D}$ is zero for a trimmed straight-and-level-flight within this $\alpha$-limit. $\delta_{T D}$ becomes different from zero due to a lateral asymmetry in the aerodynamic model for $\alpha>20^{\circ}$.
} 
8. A. Varga, G. Looye, D. Moormann, and G. Grübel. Automated generation of LFT-based parametric uncertainty descriptions from generic aircraft models. Mathematical and Computer Modelling of Dynamical Systems, 4:249-274, 1998. 